\title{
An Inventory System for Deteriorating Products with Ramp-Type Demand Rate under Two-Level Trade Credit Financing
}

\author{
G. Darzanou and K. Skouri \\ Department of Mathematics, University of Ioannina, 45110 Ioannina, Greece \\ Correspondence should be addressed to K. Skouri, kskouri@uoi.gr \\ Received 27 December 2010; Accepted 13 June 2011 \\ Academic Editor: Henry Schellhorn
}

Copyright (C) 2011 G. Darzanou and K. Skouri. This is an open access article distributed under the Creative Commons Attribution License, which permits unrestricted use, distribution, and reproduction in any medium, provided the original work is properly cited.

An inventory system for deteriorating products, with ramp-type demand rate, under two-level trade credit policy is considered. Shortages are allowed and partially backlogged. Sufficient conditions of the existence and uniqueness of the optimal replenishment policy are provided, and an algorithm, for its determination, is proposed. Numerical examples highlight the obtained results, and sensitivity analysis of the optimal solution with respect to major parameters of the system is carried out.

\section{Introduction}

In the conventional economic order quantity (EOQ) model, it is assumed that the supplier is paid for the items immediately after the items are received. In practice, the supplier may provide to the retailer a permissible delay in payments. During this credit period, the retailer can accumulate the revenue and earn interest on that revenue. However, beyond this period the supplier charges interest on the unpaid balance. Hence, a permissible delay indirectly reduces the cost of holding stock. On the other hand, trade credit offered by the supplier encourages the retailer to buy more. Thus it is also a powerful promotional tool that attracts new customers, who consider it as an alternative incentive policy to quantity discounts. Hence, trade credit can play a major role in inventory control for both the supplier as well as the retailer (see Jaggi et al. [1]). Three types of trade credit have been appeared, mainly, in the literature:

(i) a fixed trade credit period, (Goyal [2] Aggarwal and Jaggi [3], Jamal et al. [4], Chang and Dye [5], Teng [6], Jaber [7], Jaggi et al. [1], Ouyang and Cheng [8], Chung and Huang [9]); 
(ii) a two-level trade credit known as $r / M_{1} / M_{2}$. More precisely, the supplier provides $r$ discount off the price if the payment is made within period $M_{1}$; otherwise, the full payment is due within period $M_{2}$. (Huang [10], Liao [11], Teng and Chang [12]);

(iii) a trade credit period linked to the ordering quantity (Chang et al. [13], Chung and Liao [14], Ouyang et al. [15]).

For a comprehensive review for inventory lot-size models under trade credits, the reader is referred to Chang et al. [16].

In the literature referring to models with permissible delay in payments, the demand is, mostly, treated either as constant or as continuous differentiable function of time. However, in the case of a new brand of consumer good coming to the market, its demand rate increases in its growth stage (i.e., $[0, \mu]$ ) and then remains stable in its maturity stage (i.e., $[\mu, T]$ ). In addition, the demand rate of a seasonable product increases at the beginning of the season up to a certain moment (say, $\mu$ ) and then remains constant for the rest of the planning horizon, $T$. The term "ramp-type" is used to represent such demand pattern. Hill [17] proposed an inventory model with variable branch being any power function of time. Research on this field continues with Mandal and Pal [18], Wu and Ouyang [19], and Wu [20]. In the abovecited papers, the optimal replenishment policy requires to determine the decision time (say, $t_{1}$ ) at which the inventory level falls to zero. Consequently, the following two cases should be examined: (1) the inventory level fall to zero before the demand reaches constant (i.e., $t_{1}<\mu$ ) and (2) the inventory level falls to zero after the demand reaches constant (i.e., $t_{1}>\mu$ ). Almost all of the researchers examined only the first case. Deng et al. [21] first reconsidered the inventory models proposed by Mandal and Pal [18] and Wu and Ouyang [19] and discussed both cases. Panda et al. [22] developed an inventory model for deteriorating items (with three-parameter Weibull distributed deterioration rate) with generalized exponential ramp-type demand rate and complete backlogging. Skouri et al. [23] extend the work of Deng et al. [21] by introducing a general ramp-type demand rate and Weibull deterioration rate. Panda et al. [24] presented a production-inventory model with generalized quadratic ramp-type demand rate and constant deterioration rate when shortages are not allowed. Skouri and Konstantaras [25] extended their previous work [23] studying an order level inventory model for deteriorating items based on time-dependent three branches ramp-type demand rate. Lin [26] studied an inventory model with general ramp-type demand rate, constant deterioration rate, complete backlogging, and several replenishment cycles during the finite time and used the hide-and-seek simulated annealing (SA) approach to determine the optimal replenishment policy.

This paper is an extension of the inventory system of Skouri et al. [23] assuming constant deterioration rate, when the two-level trade credit scheme, $r / M_{1} / M_{2}$, which was described above, is considered. The study of this system requires the examination of the ordering relations between the time parameters $M_{1}, M_{2}, \mu, T$, which, actually, lead to the following different models:

(i) $M_{1} \leq \mu<M_{2}<T$, (ii) $M_{1}<M_{2} \leq \mu<T$, (iii) $\mu \leq M_{1}<M_{2}<T$, (iv) $\mu \leq M_{1}<T<$ $M_{2}$, (v) $\mu<T \leq M_{1}<M_{2}$, (vi) $M_{1} \leq \mu<T \leq M_{2}$.

Note that from the definition of demand rate $\mu<T$ and from credit scheme $M_{1}<M_{2}$.

This study can be used: (1) for the determination of the optimal replenishment policy under a specific trade credit settings (corresponding to one of the six models mentioned above) and (2) for supplier' selection, since it is obvious that the ordering of the parameters $\mu, M_{1}, M_{2}, T$ leads to different trade credit offers. Although the analysis of all models is 
available upon request, in order to reduce the length of the paper, only the first model will be presented.

The paper is organized as follows: the notation and assumptions used are given in Section 2. In Section 3, the quantities and functions, which are common to each of the possible models are derived. The mathematical formulation of the first model and the determination of the optimal policy are provided in Section 4. In Section 5, numerical examples highlighting the results obtained are given, and sensitivity analysis with respect to major parameters of the system is carried out. The paper closes with concluding remarks in Section 6.

\section{Notation and Assumptions}

The following notation is used through the paper.

\subsection{Notation}

$T$ is the constant scheduling period (cycle),

$t_{1}$ the time when the inventory level falls to zero,

$S$ the maximum inventory level at each scheduling period (cycle),

$C_{p}$ the unit purchase cost,

$c_{1}$ the inventory holding cost per unit per unit time,

$c_{2}$ the shortage cost per unit per unit time,

$c_{3}$ the cost incurred from the deterioration of one unit,

$c_{4}$ the per unit opportunity cost due to the lost sales $\left(c_{4}>C_{p}\right.$ see Teng et al. [27]),

$p$ the unit selling price,

$I_{e}$ the interest rate earned,

$I_{c}$ the interest rate charged,

$r$ cash discount rate, $0<r<1$,

$M_{1}$ the period of cash discount in years,

$M_{2}$ the period of permissible delay in payments in years, $M_{1}<M_{2}$,

$\mu$ the parameter of the ramp-type demand function (time point), and

$I(t)$ the inventory level at time $t$.

\subsection{Assumptions}

The inventory model is developed under the following assumptions.

(1) The ordering quantity brings the inventory level up to the order level $S$. Replenishment rate is infinite.

(2) Shortages are backlogged at a rate $\beta(x)$ which is a nonincreasing function of $x$ with $0<\beta(x) \leq 1, \beta(0)=1$ and $x$ is the waiting time up to the next replenishment. Moreover, it is assumed that $\beta(x)$ satisfies the relation $C_{2} \beta(x)+C_{2} T \beta^{\prime}(x)+C_{p} \beta^{\prime}(x) \geq$ 0 , where $\beta^{\prime}(x)$ is the derivate of $\beta(x)$. The case with $\beta(x)=1$ corresponds to complete backlogging model. 
(3) The supplier offers cash discount if payment is paid within $M_{1}$; otherwise, the full payment is paid within $M_{2}$, (see Huang [10]).

(4) The on-hand inventory deteriorates at a constant rate $\theta(0<\theta<1)$ per time unit. The deteriorated items are withdrawn immediately from the warehouse and there is no provision for repair or replacement.

(5) The demand rate $D(t)$ is a ramp-type function of time given by

$$
D(t)= \begin{cases}f(t), & t<\mu, \\ f(\mu), & t \geq \mu,\end{cases}
$$

where $f(t)$ is a positive, differentiable function of $t \in(0, T]$.

\section{Deriving the Common Quantities for the Inventory Models}

In this section, common quantities entering to all models will be derived. Note that these quantities are affected only by the ordering relations between $t_{1}$ and $\mu$. The inventory level $I(t), 0 \leq t \leq T$ satisfies the following differential equations:

$$
\frac{d I(t)}{d t}+\theta I(t)=-D(t), \quad 0 \leq t \leq t_{1}
$$

with boundary condition $I\left(t_{1}\right)=0$ and

$$
\frac{d I(t)}{d t}=-D(t) \beta(T-t), \quad t_{1} \leq t \leq T
$$

with boundary condition $I\left(t_{1}\right)=0$.

From the two possible relations between parameters $t_{1}$ and $\mu$, (i) $t_{1} \leq \mu$ and (ii) $t_{1}>$ $\mu$, and following identical steps as in Skouri et al. [23], the sum of holding, deterioration, shortages, and lost sales cost is obtained as

$$
C\left(t_{1}\right)= \begin{cases}C_{1}\left(t_{1}\right) & \text { if } t_{1} \leq \mu, \\ C_{2}\left(t_{1}\right) & \text { if } t_{1}>\mu,\end{cases}
$$

where

$$
\begin{aligned}
C_{1}\left(t_{1}\right)= & c_{1}\left\{\int_{0}^{t_{1}} e^{-\theta t}\left[\int_{t}^{t_{1}} f(x) e^{\theta x} d x\right] d t\right\} \\
& +c_{2}\left\{\int_{t_{1}}^{\mu}(\mu-t) f(t) \beta(T-t) d t+f(\mu) \int_{\mu}^{T}\left[\int_{\mu}^{t} \beta(T-x) d x\right] d t\right.
\end{aligned}
$$




$$
\begin{aligned}
&+\left.\int_{\mu}^{T}\left[\int_{t_{1}}^{\mu} f(x) \beta(T-x) d x\right] d t\right\} \\
&+ c_{3}\left\{\int_{0}^{t_{1}} f(t) e^{\theta t} d t-\int_{0}^{t_{1}} f(t) d t\right\} \\
&+ c_{4}\left\{\int_{t_{1}}^{\mu}(1-\beta(T-t)) f(t) d t+f(\mu) \int_{\mu}^{T}(1-\beta(T-t)) d t\right\}, \\
& C_{2}\left(t_{1}\right)=c_{1}\left\{\int_{0}^{\mu} e^{-\theta t}\left[\int_{t}^{\mu} f(x) e^{\theta x} d x+f(\mu) \int_{\mu}^{t_{1}} e^{\theta x} d x\right] d t\right. \\
&\left.+\quad f(\mu) \int_{\mu}^{t_{1}} e^{-\theta t}\left[\int_{t}^{t_{1}} e^{\theta x} d x\right] d t\right\} \\
&+c_{3}\left\{\int_{0}^{\mu} f(t) e^{\theta t} d t+f(\mu) \int_{\mu}^{t_{1}} e^{\theta t} d t-\int_{0}^{\mu} f(t) d t-f(\mu)\left(t_{1}-\mu\right)\right\} \\
&+c_{2}\left\{f(\mu) \int_{t_{1}}^{T}(T-x) \beta(T-x) d x\right\}+c_{4}\left\{f(\mu) \int_{t_{1}}^{T}(1-\beta(T-t)) d t\right\} .
\end{aligned}
$$

\section{Model I-The Inventory Model When $M_{1} \leq \mu<M_{2}<T$}

In order to obtain the total cost for this model, the purchasing cost, interest charges for the items kept in stock, and the interest earned should be taken into account.

Since the supplier offers cash discount if payment is paid within $M_{1}$, there are two payment policies for the buyer. Either the payment is paid at time $M_{1}$ to receive the cash discount (Case 1) or the payment is paid at time $M_{2}$ so as not to receive the cash discount (Case 2). Then, these two cases will be discussed.

Case 1 (payment is made at time $M_{1}$ ). In this case, the following subcases should be considered.

Subcase $1.1\left(t_{1} \leq M_{1} \leq \mu<T\right)$. The purchasing cost is

$$
C_{A 1,1}\left(t_{1}\right)=C_{p}(1-r)\left[\int_{0}^{t_{1}} f(x) e^{\theta x} d x+f(\mu) \int_{\mu}^{T} \beta(T-x) d x+\int_{t_{1}}^{\mu} f(x) \beta(T-x) d x\right] .
$$

The interest earned during the period of positive inventory level is

$$
I_{T 1,1}\left(t_{1}\right)=p I_{e} \int_{0}^{t_{1}} \int_{0}^{t} f(x) d x d t+p I_{e}\left(M_{1}-t_{1}\right) \int_{0}^{t_{1}} f(x) d x
$$


Since $t_{1} \leq \mu$, the total cost in the time interval $[0, T]$ is calculated using (3.4), (4.1), and (4.2)

$$
T C_{11}\left(t_{1}\right)=C_{1}\left(t_{1}\right)+C_{A 1,1}\left(t_{1}\right)-I_{T 1,1}\left(t_{1}\right)
$$

Subcase $1.2\left(M_{1}<t_{1} \leq \mu<T\right)$. The purchasing cost is $C_{A 1,1}$ (relation (4.1)).

The interest payable for the inventory not being sold after the due date $M_{1}$ is

$$
P_{T 2,1}\left(t_{1}\right)=C_{p}(1-r) I_{c} \int_{M_{1}}^{t_{1}} e^{-\theta t}\left[\int_{t}^{t_{1}} f(x) e^{\theta x}\right] d x d t
$$

The interest earned is

$$
I_{T 2,1}\left(t_{1}\right)=p I_{e} \int_{0}^{t_{1}} \int_{0}^{t} f(x) d x d t
$$

Since again $t_{1} \leq \mu$, the total cost over $[0, T]$ is calculated using the relations (3.4), (4.1), (4.4), and (4.6) and is

$$
T C_{12}\left(t_{1}\right)=C_{1}\left(t_{1}\right)+C_{A 1,1}\left(t_{1}\right)+P_{T 2,1}\left(t_{1}\right)-I_{T 2,1}\left(t_{1}\right) .
$$

Subcase $1.3\left(M_{1} \leq \mu \leq t_{1} \leq T\right)$. The purchasing cost is

$$
C_{A 2,1}\left(t_{1}\right)=C_{p}(1-r)\left[\int_{0}^{\mu} f(x) e^{\theta x} d x+f(\mu) \int_{\mu}^{t_{1}} e^{\theta x} d x+f(\mu) \int_{t_{1}}^{T} \beta(T-x) d x\right] .
$$

The interest earned, $I_{T 3,1}$, is:

$$
I_{T 3,1}\left(t_{1}\right)=p I_{e}\left(\int_{0}^{\mu} \int_{0}^{t} f(x) d x d t+\int_{\mu}^{t_{1}} \int_{0}^{\mu} f(x) d x d t+\int_{\mu}^{t_{1}} \int_{\mu}^{t} f(\mu) d x d t\right) .
$$

The interest payable for the inventory not being sold after the due date $M_{1}$ is

$$
\begin{aligned}
P_{T 3,1}\left(t_{1}\right)=C_{p}(1-r) I_{c} & \left(\int_{M_{1}}^{\mu} e^{-\theta t} \int_{t}^{\mu} e^{\theta x} f(x) d x d t\right. \\
& \left.+f(\mu) \int_{M_{1}}^{\mu} e^{-\theta t} \int_{\mu}^{t_{1}} e^{\theta x} d x d t+f(\mu) \int_{\mu}^{t_{1}} e^{-\theta t} \int_{t}^{t_{1}} e^{\theta x} d x d t\right) .
\end{aligned}
$$

Since $\mu<t_{1}$, the total cost over $[0, T]$ is again calculated from (3.5), (4.7)-(4.9) and is

$$
T C_{13}\left(t_{1}\right)=C_{2}\left(t_{1}\right)+C_{A 2,1}\left(t_{1}\right)+P_{T 3,1}\left(t_{1}\right)-I_{T 3,1}\left(t_{1}\right) .
$$


The results obtained lead to the following total cost function:

$$
T C_{1}\left(t_{1}\right)= \begin{cases}T C_{1,1}\left(t_{1}\right), & t_{1} \leq M_{1} \\ T C_{1,2}\left(t_{1}\right), & M_{1}<t_{1} \leq \mu, \\ T C_{1,3}\left(t_{1}\right), & \mu \leq t_{1} .\end{cases}
$$

So the problem is

$$
\min _{t_{1}} T C_{1}\left(t_{1}\right)
$$

Its solution requires, separately, studying each of three branches and then combining the results to obtain the optimal policy. It is easy to check that $T C_{1}\left(t_{1}\right)$ is continuous at the points $M_{1}$ and $\mu$.

The first-order condition for a minimum of $T C_{1,1}\left(t_{1}\right)$ is

$$
\begin{aligned}
\frac{d T C_{1,1}\left(t_{1}\right)}{d t_{1}}=\{ & \frac{c_{1}+c_{3} \theta}{\theta}\left(e^{\theta t_{1}}-1\right)-c_{2}\left(T-t_{1}\right) \beta\left(T-t_{1}\right) \\
& \left.-c_{4}\left(1-\beta\left(T-t_{1}\right)\right)-p I_{e}\left(M_{1}-t_{1}\right)+C_{p}(1-r)\left(e^{\theta t_{1}}-\beta\left(T-t_{1}\right)\right)\right\} f\left(t_{1}\right)=0 .
\end{aligned}
$$

Since $d T C_{1,1}(0) / d t_{1}<0$ and $d T C_{1,1}(T) / d t_{1}>0,(4.13)$ has at least one root. So if $t_{1,1}$ is the root of (4.13), this corresponds to minimum since

$$
\begin{array}{r}
\left.\frac{d T C_{1,1}^{2}\left(t_{1}\right)}{d t_{1}^{2}}\right|_{t_{1}=t_{1,1}}=f\left(t_{1,1}\right)\{( \\
\left(c_{1}+c_{3} \theta\right) e^{\theta t_{1,1}}+c_{2} \beta\left(T-t_{1,1}\right)+c_{2}\left(T-t_{1,1}\right) \beta^{\prime}\left(T-t_{1,1}\right) \\
\left.\quad-c_{4} \beta^{\prime}\left(T-t_{1,1}\right)+p I_{e}+C_{p}(1-r)\left(\theta e^{\theta t_{1,1}}+\beta^{\prime}\left(T-t_{1,1}\right)\right)\right\}>0 .
\end{array}
$$

Consequently, $t_{1,1}$ is the unique unconstrained minimum of $T C_{1,1}\left(t_{1}\right)$.

The first-order condition for a minimum of $T C_{1,2}\left(t_{1}\right)$ is

$$
\begin{aligned}
\frac{d T C_{1,2}\left(t_{1}\right)}{d t_{1}}= & \frac{c_{1}+c_{3} \theta}{\theta}\left(e^{\theta t_{1}}-1\right) f\left(t_{1}\right)-c_{2}\left(T-t_{1}\right) \beta\left(T-t_{1}\right) f\left(t_{1}\right)-c_{4}\left(1-\beta\left(T-t_{1}\right)\right) f\left(t_{1}\right) \\
& +C_{p}(1-r)\left(e^{\theta t_{1}}-\beta\left(T-t_{1}\right)\right)+\frac{C_{p}(1-r) I_{c}}{\theta}\left(e^{\theta\left(t_{1}-M_{1}\right)}-1\right) f\left(t_{1}\right) \\
& -p I_{e} \int_{0}^{t_{1}} f(x) d x=0 .
\end{aligned}
$$


Let us set $h(x)=c_{2} x \beta(x)+c_{4}(1-\beta(x))-p I_{e} x$. If $t_{1,2}$ is the root of (4.15) (this may or may not exist), $f(x)$ is an increasing function and further if $h^{\prime}(x)>0$, then

$$
\begin{aligned}
\left.\frac{d^{2} T C_{1,2}\left(t_{1}\right)}{d t_{1}^{2}}\right|_{t_{1}=t_{1,2}}= & p I_{e} f^{\prime}\left(t_{1,2}\right) \\
+f\left(t_{1,2}\right) & \left\{\left(c_{1}+c_{3} \theta\right) e^{\theta t_{1,2}}+c_{2}\left[\beta\left(T-t_{1,2}\right)+\left(T-t_{1,2}\right) \beta^{\prime}\left(T-t_{1,2}\right)\right]\right. \\
& -c_{4} \beta^{\prime}\left(T-t_{1,2}\right)+C_{p}(1-r) I_{c} e^{\theta\left(t_{1,2}-M_{1}\right)} \\
& \left.+C_{p}(1-r)\left(\theta e^{\theta t_{1,2}}+\beta^{\prime}\left(T-t_{1,2}\right)\right)-p I_{e}\right\}>0,
\end{aligned}
$$

and this $t_{1,2}$ corresponds to unconstrained minimum of $T C_{1,2}\left(t_{1}\right)$.

The first-order condition for a minimum of $T C_{1,3}\left(t_{1}\right)$ is

$$
\begin{aligned}
& \frac{d T C_{1,3}\left(t_{1}\right)}{d t_{1}}=f(\mu)\left\{\frac{c_{1}+c_{3} \theta}{\theta}\left(e^{\theta t_{1}}-1\right)-c_{2}\left(T-t_{1}\right) \beta\left(T-t_{1}\right)-c_{4}\left(1-\beta\left(T-t_{1}\right)\right)\right. \\
& \left.\quad-p I_{e}\left(t_{1}-\mu\right)+\frac{C_{p}(1-r) I_{c}}{\theta}\left(e^{\theta\left(t_{1}-M_{1}\right)}-1\right)+C_{p}(1-r)\left(e^{\theta t_{1}}-\beta\left(T-t_{1}\right)\right)\right\} \\
& \quad-p I_{e} \int_{0}^{\mu} f(x) d x=0 .
\end{aligned}
$$

If $t_{1,3}$ is the root of (4.17) (this may or may not exist) and $h^{\prime}(x)>0$, then

$$
\begin{aligned}
\frac{d^{2} T C_{1,3}\left(t_{1}\right)}{d t_{1}^{2}}=( & \left(c_{1}+c_{3} \theta\right) e^{\theta t_{1}}+c_{2}\left[\beta\left(T-t_{1}\right)+\left(T-t_{1}\right) \beta^{\prime}\left(T-t_{1}\right)\right]-c_{4} \beta^{\prime}\left(T-t_{1}\right) \\
& \left.-p I_{e}+C_{p}(1-r) I_{c} e^{\theta\left(t_{1}-M_{1}\right)}+C_{p}(1-r)\left(\theta e^{\theta t_{1}}+\beta^{\prime}\left(T-t_{1}\right)\right)\right) f(\mu)>0,
\end{aligned}
$$

this $t_{1,3}$ corresponds to unconstrained minimum of $T C_{1,3}\left(t_{1}\right)$.

Remark 4.1. The function $T C_{1}\left(t_{1}\right)$ is not differentiable in $M_{1}$.

Then, the following procedure summarizes the previous results for the determination of the optimal replenishment policy, when payment is made at time $M_{1}$.

Step 1. Find the global minimum of $T C_{1,1}\left(t_{1}\right)$, say $t_{1,1, M_{1}}^{*}$, as follows.

Substep 1.1. Compute $t_{1,1, M_{1}}$ from (4.13); if $t_{1,1, M_{1}}<M_{1}$, then set $t_{1,1, M_{1}}^{*}=t_{1,1, M_{1}}$ and compute $T C_{1,1}\left(t_{1,1, M_{1}}^{*}\right)$ else go to Substep 1.2.

Substep 1.2. Find the $\min \left\{T C_{1,1}(0), T C_{1,1}\left(M_{1}\right)\right\}$ and accordingly set $t_{1,1, M_{1}}^{*}$.

Step 2. Find the global minimum of $T C_{1,2}\left(t_{1}\right)$, say $t_{1,2, M_{1}}^{*}$, as follows. 
Substep 2.1. Compute $t_{1,2, M_{1}}$ from (4.15); if $M_{1}<t_{1,2, M_{1}}<\mu$, then set $t_{1,2, M_{1}}^{*}=t_{1,2, M_{1}}$ and compute $T C_{2}\left(t_{1,2, M_{1}}^{*}\right)$ else go to Substep 2.2.

Substep 2.2. Find the $\min \left\{T C_{1,2}\left(M_{1}\right), T C_{1,2}(\mu)\right\}$ and accordingly set $t_{1,2, M_{1}}^{*}$.

Step 3. Find the global minimum of $T C_{1,3}\left(t_{1}\right)$, say $t_{1,3, M_{1}}^{*}$, as follows.

Substep 3.1. Compute $t_{1,3, M_{1}}$ from (4.17); if $\mu<t_{1,3, M_{1}}$, then set $t_{1,3, M_{1}}^{*}=t_{1,3, M_{1}}$ and compute $T C_{1,3}\left(t_{1,3, M_{1}}^{*}\right)$ else go to Substep 3.2.

Substep 3.2. Find the $\min \left\{T C_{1,3}(\mu), T C_{1,3}(T)\right\}$ and accordingly set $t_{1,3, M_{1}}^{*}$.

Step 4. Find the $\min \left\{T C_{1,1}\left(t_{1,1, M_{1}}^{*}\right), T C_{1,2}\left(t_{1,2, M_{1}}^{*}\right), T C_{1,3}\left(t_{1,3, M_{1}}^{*}\right)\right\}$ and accordingly select the optimal value for $t_{1}$ say $t_{1, M_{1}}$ with optimal cost $C_{1}\left(t_{1, M_{1}}\right)$.

Case 2 (payment is made at time $M_{2}$ ). When the payment is made at time $M_{2}$ the following cases should be considered.

Subcase $2.1\left(t_{1} \leq \mu<M_{2}<T\right)$. The purchasing cost is.

$$
C_{A 1,2}\left(t_{1}\right)=\frac{C_{A 1,1}\left(t_{1}\right)}{1-r}
$$

The interest earned during the period of positive inventory level is.

$$
I_{T 1,2}\left(t_{1}\right)=p I_{e} \int_{0}^{t_{1}} \int_{0}^{t} f(x) d x d t+p I_{e}\left(M_{2}-t_{1}\right) \int_{0}^{t_{1}} f(x) d x
$$

Since $t_{1} \leq \mu$, the total cost in the time interval $[0, T]$ is calculated using (3.4), (4.19), and (4.20)

$$
T C_{2,1}\left(t_{1}\right)=C_{1}\left(t_{1}\right)+C_{A 1,2}\left(t_{1}\right)-I_{T 1,2}\left(t_{1}\right)
$$

Subcase $2.2\left(\mu<t_{1} \leq M_{2}<T\right)$. The purchasing cost is

$$
C_{A 2,2}=\frac{C_{A 2,1}\left(t_{1}\right)}{1-r} .
$$

The interest earned is

$$
\begin{aligned}
I_{T 2,2}\left(t_{1}\right)=p I_{e}[ & {\left[\int_{0}^{\mu} \int_{0}^{t} f(x) d x d t+\int_{\mu}^{M_{2}} \int_{0}^{\mu} f(x) d x d t+\int_{\mu}^{t_{1}} \int_{\mu}^{t} f(\mu) d x d t\right.} \\
& \left.+\int_{t_{1}}^{M_{2}} \int_{\mu}^{t_{1}} f(\mu) d x d t\right] .
\end{aligned}
$$


Since again $\mu \leq t_{1}$, the total cost over $[0, T]$ is calculated using the relations (3.5), (4.22), and (4.23) and is

$$
T C_{2,2}\left(t_{1}\right)=C_{2}\left(t_{1}\right)+C_{A 2,2}\left(t_{1}\right)-I_{T 2,2}\left(t_{1}\right)
$$

Subcase 2.3 ( $\left.\mu \leq M_{2} \leq t_{1} \leq T\right)$. The purchasing cost is $C_{A 2,2}\left(t_{1}\right)$.

The interest earned, $I_{T 3,2}$, is

$$
I_{T 3,2}\left(t_{1}\right)=p I_{e}\left(\int_{0}^{\mu} \int_{0}^{t} f(x) d x d t+\int_{\mu}^{t_{1}} \int_{0}^{\mu} f(x) d x d t+\int_{\mu}^{t_{1}} \int_{\mu}^{t} f(\mu) d x d t\right) .
$$

The interest payable for the inventory not being sold after the due date $M_{2}$ is

$$
P_{T 3,2}\left(t_{1}\right)=C_{p} I_{c} f(\mu) \int_{M_{2}}^{t_{1}} e^{-\theta t} \int_{t}^{t_{1}} e^{\theta x} d x d t
$$

Since $\mu<t_{1}$, the total cost over $[0, T]$ is again calculated from (3.5), (4.22), (4.25), and (4.26) and is

$$
T C_{2,3}\left(t_{1}\right)=C_{2}\left(t_{1}\right)+C_{A 2,2}\left(t_{1}\right)+P_{T 3,2}\left(t_{1}\right)-I_{T 3,2}\left(t_{1}\right) .
$$

The results obtained lead to the following total cost function:

$$
T C_{2}\left(t_{1}\right)= \begin{cases}T C_{2,1}\left(t_{1}\right), & t_{1} \leq \mu \\ T C_{2,2}\left(t_{1}\right), & \mu<t_{1} \leq M_{2} \\ T C_{2,3}\left(t_{1}\right), & M_{2} \leq t_{1} .\end{cases}
$$

So the problem is

$$
\min _{t_{1}} T C_{2}\left(t_{1}\right)
$$

Its solution, as in the previous case, requires, separately, studying each of three branches and then combining the results to obtain the optimal policy. It is easy to check that $T C_{2}\left(t_{1}\right)$ is continuous at the points $M_{2}$ and $\mu$.

The first-order condition for the minimum for $T C_{2,1}\left(t_{1}\right)$ is

$$
\begin{aligned}
\frac{d T C_{2,1}\left(t_{1}\right)}{d t_{1}}=\{ & \frac{c_{1}+c_{3} \theta}{\theta}\left(e^{\theta t_{1}}-1\right)-c_{2}\left(T-t_{1}\right) \beta\left(T-t_{1}\right)-c_{4}\left(1-\beta\left(T-t_{1}\right)\right) \\
& \left.-p I_{e}\left(M_{2}-t_{1}\right)+C_{p}\left(e^{\theta t_{1}}-\beta\left(T-t_{1}\right)\right)\right\} f\left(t_{1}\right)=0 .
\end{aligned}
$$


Since $d T C_{2,1}(0) / d t_{1}<0$ and $d T C_{2,1}(T) / d t_{1}>0,(4.30)$ has at least one root. So if $t_{1,1}$ is the root of (4.30), this corresponds to minimum as

$$
\begin{array}{r}
\left.\frac{d T C_{2,1}^{2}\left(t_{1}\right)}{d t_{1}^{2}}\right|_{t_{1}=t_{1,1}}=f\left(t_{1,1}\right)\{( \\
\left.c_{1}+c_{3} \theta\right) e^{\theta t_{1,1}}+c_{2} \beta\left(T-t_{1,1}\right)+c_{2}\left(T-t_{1,1}\right) \beta^{\prime}\left(T-t_{1,1}\right) \\
\left.-c_{4} \beta^{\prime}\left(T-t_{1,1}\right)+p I_{e}+C_{p}\left(\theta e^{\theta t_{1,1}}+\beta^{\prime}\left(T-t_{1,1}\right)\right)\right\}>0
\end{array}
$$

So $t_{1,1}$ is the unconstrained minimum of $T C_{2,1}\left(t_{1}\right)$.

The first-order condition for a minimum of $T C_{2,2}\left(t_{1}\right)$ is

$$
\begin{gathered}
\frac{d T C_{2,2}\left(t_{1}\right)}{d t_{1}}=f(\mu)\left\{\frac{c_{1}+c_{3} \theta}{\theta}\left(e^{\theta t_{1}}-1\right)-c_{2}\left(T-t_{1}\right) \beta\left(T-t_{1}\right)-c_{4}\left(1-\beta\left(T-t_{1}\right)\right)\right. \\
\left.-p I_{e}\left(M_{2}-t_{1}\right)+C_{p}\left(e^{\theta t_{1}}-\beta\left(T-t_{1}\right)\right)\right\}=0
\end{gathered}
$$

If $t_{1,2}$ is the root of (4.32) (this may or may not exist), this corresponds to unconstrained minimum of $T C_{2,2}\left(t_{1}\right)$ as

$$
\begin{array}{r}
\left.\frac{d T C_{2,2}^{2}\left(t_{1}\right)}{d t_{1}^{2}}\right|_{t_{1}=t_{1,2}}=f(\mu)\{( \\
\left.c_{1}+c_{3} \theta\right) e^{\theta t_{1,2}}+c_{2} \beta\left(T-t_{1,2}\right)+c_{2}\left(T-t_{1,2}\right) \beta^{\prime}\left(T-t_{1,2}\right) \\
\left.-c_{4} \beta^{\prime}\left(T-t_{1,2}\right)+p I_{e}+C_{p}\left(\theta e^{\theta t_{1,2}}+\beta^{\prime}\left(T-t_{1,2}\right)\right)\right\}>0 .
\end{array}
$$

The first-order condition for a minimum of $T C_{2,3}\left(t_{1}\right)$ is

$$
\begin{gathered}
\frac{d T C_{2,3}\left(t_{1}\right)}{d t_{1}}=f(\mu)\left\{\frac{c_{1}+c_{3} \theta}{\theta}\left(e^{\theta t_{1}}-1\right)-c_{2}\left(T-t_{1}\right) \beta\left(T-t_{1}\right)-c_{4}\left(1-\beta\left(T-t_{1}\right)\right)-p I_{e}\left(t_{1}-\mu\right)\right. \\
\left.+\frac{C_{p} I_{c}}{\theta}\left(e^{\theta\left(t_{1}-M_{2}\right)}-1\right)+C_{p}\left(e^{\theta t_{1}}-\beta\left(T-t_{1}\right)\right)\right\}-p I_{e} \int_{0}^{\mu} f(x) d x=0 .
\end{gathered}
$$

If $t_{1,3}$ is a root of (4.34) (this may or may not exist) and $c_{1}+c_{3} \theta+C_{p} I_{c} \geq p I_{e}$ this corresponds to unconstrained minimum of $T C_{2,3}\left(t_{1}\right)$ as

$$
\begin{gathered}
\frac{d T C_{2,3}^{2}\left(t_{1}\right)}{d t_{1}^{2}}=\left\{\left(c_{1}+c_{3} \theta+C_{p} I_{c}\right) e^{\theta t_{1}}+c_{2} \beta\left(T-t_{1}\right)+c_{2}\left(T-t_{1}\right) \beta^{\prime}\left(T-t_{1}\right)\right. \\
\left.-c_{4} \beta^{\prime}\left(T-t_{1}\right)-p I_{e}+C_{p}\left(\theta e^{\theta t_{1}}+\beta^{\prime}\left(T-t_{1}\right)\right)\right\} f(\mu) .
\end{gathered}
$$

Remark 4.2. The function $T C_{2}\left(t_{1}\right)$ is not differentiable in $M_{2}$. 
The procedure for the determination of the optimal replenishment policy when payment is made at time $M_{2}$ is as follows.

Step 1. Find the global minimum of $T C_{2,1}\left(t_{1}\right)$, say $t_{1,1, M_{2}}^{*}$ as follows.

Substep 1.1. Compute $t_{1,1, M_{2}}$ from (4.30); if $t_{1,1, M_{2}}<\mu$, then set $t_{1,1, M_{2}}^{*}=t_{1,1, M_{2}}$ and compute $T C_{2,1}\left(t_{1,1, M_{2}}^{*}\right)$ else go to Substep 1.2.

Substep 1.2. Find the $\min \left\{T C_{2,1}(0), T C_{2,1}(\mu)\right\}$ and accordingly set $t_{1,1, M_{2}}^{*}$.

Step 2. Find the global minimum of $T C_{2,2}\left(t_{1}\right)$, say $t_{1,2, M_{2}}^{*}$, as follows.

Substep 2.1. Compute $t_{1,2, M_{2}}$ from (4.32); if $\mu<t_{1,2, M_{2}}<M_{2}$, then set $t_{1,2, M_{2}}^{*}=t_{1,2, M_{2}}$ and compute $T C_{2,2}\left(t_{1,2, M_{2}}^{*}\right)$ else go to Substep 2.2.

Substep 2.2. Find the $\min \left\{T C_{2,2}(\mu), T C_{2,2}\left(M_{2}\right)\right\}$ and accordingly set $t_{1,2, M_{2}}^{*}$.

Step 3. Find the global minimum of $T C_{2,3}\left(t_{1}\right)$, say $t_{1,3, M_{2}}^{*}$, as follows.

Substep 3.1. Compute $t_{1,3, M_{2}}$ from (4.34); if $M_{2}<t_{1,3, M_{2}}<T$, then set $t_{1,3, M_{2}}^{*}=t_{1,3, M_{2}}$ and compute $T C_{2,3}\left(t_{1,3, M_{2}}^{*}\right)$ else go to Substep 3.2.

Substep 3.2. Find the $\min \left\{T C_{2,3}\left(M_{2}\right), T C_{2,3}(T)\right\}$ and accordingly set $t_{1,3, M_{2}}^{*}$.

Step 4. Find the $\min \left\{T C_{2,1}\left(t_{1,1, M_{2}}^{*}\right), T C_{2,2}\left(t_{1,2, M_{2}}^{*}\right), T C_{2,3}\left(t_{1,3, M_{2}}^{*}\right)\right\}$ and accordingly select the optimal value for $t_{1}$ say $t_{1, M_{2}}$ with optimal cost $T C_{2}\left(t_{1, M_{2}}\right)$.

Finally to find the overall optimum $t_{1}$ for the problem under consideration, the results obtained for the two presented cases (i.e., payment is made at $M_{1}$ and payment is made at $\left.M_{2}\right)$ are combined, that is, find $\min \left\{T C_{1}\left(t_{1, M_{1}}\right), T C_{2}\left(t_{1, M_{2}}\right)\right\}$ and accordingly select the optimal value $t_{1}^{*}$.

\section{Numerical Examples and Sensitivity Analysis}

In this section, a numerical example is provided to illustrate the results obtained in previous sections. In addition, a sensitivity analysis, with respect to some important model's parameters, is carried out.

The input parameters are $c_{1}=3 €$ per unit per unit time, $c_{2}=15 €$ per unit per unit time, $c_{3}=5 €$ per unit, $c_{4}=20 €$ per unit per unit time, $r=0.005, \mu=0.3$ years, $\theta=0.001$, $T=0.5$ years, $f(t)=3 e^{4.5 t}$ and $\beta(x)=e^{-0.2 x}, M_{1}=0.13$ years, $M_{2}=0.43$ years, $p=15, C_{p}=10$, $I_{e}=0.12, I_{c}=0.15$.

\subsection{The Payment Is Made at $M_{1}$}

From (4.13), $t_{1,1, M_{1}}=0.399$, which is not feasible as $t_{1,1, M_{1}}>M_{1}$. Since $T C_{1,1}(0)=55.469$ and $T C_{1,1}\left(M_{1}\right)=51.9633$, it follows that $t_{1,1, M_{1}}^{*}=M_{1}$. From (4.15), $t_{1,2, M_{1}}=0.426$, which is not valid again as $t_{1,2, M_{1}}>\mu$. Since $T C_{1,1}\left(M_{1}\right)=T C_{1,2}\left(M_{1}\right)=51.9633$ and $T C_{1,2}(\mu)=46.6669$, the optimal value for $t_{1,2, M_{1}}^{*}=\mu$. From (4.17) $t_{1,3, M_{1}}=0.423$; this value for $t_{1}$ is valid as $\mu<t_{1,3, M_{1}}<$ $T$ so $t_{1,3, M_{1}}^{*}=t_{1,3, M_{1}}$ and $T C_{1,3}\left(t_{1,3, M_{1}}^{*}\right)=44.8287$.

Finally $T C_{1,3}\left(t_{1,3, M_{1}}^{*}\right)=\min \left\{T C_{1,1}\left(M_{1}\right), T C_{1,2}(\mu), T C_{1,3}\left(t_{1,3, M_{1}}^{*}\right)\right\}=44.8287$ and consequently $t_{1, M_{1}}^{*}=0.423$. 
Table 1: Sensitivity analysis: the effect of changing the parameter (i) keeping all other parameters unchanged.

\begin{tabular}{ccccc}
\hline Parameter $(i)$ & Percentage of changes $(\%)$ & $t_{1}^{*}$ & Time of payment & $T C\left(t_{1}^{*}\right)$ \\
\hline \multirow{4}{*}{$\mu$} & -50 & 0.46 & $M_{2}$ & 27.0538 \\
& -25 & 0.44 & $M_{2}$ & 44.4206 \\
& +25 & 0.45 & $M_{2}$ & 52.8972 \\
& +50 & 0.45 & $M_{2}$ & 58.8673 \\
\hline \multirow{3}{*}{$M_{1}$} & -50 & 0.451 & $M_{2}$ & 44.3039 \\
& -25 & 0.451 & $M_{2}$ & 44.3039 \\
& +25 & 0.451 & $M_{2}$ & 44.3039 \\
& +50 & 0.451 & $M_{2}$ & 44.3039 \\
$M_{2}$ & -50 & 0.434 & $M_{2}$ & 44.4075 \\
& -25 & 0.443 & $M_{2}$ & 44.4206 \\
& +25 & 0.43 & $M_{2}$ & 43.6966 \\
& +50 & 0.43 & $M_{2}$ & 43.5449 \\
\hline & -50 & 0.451 & $M_{2}$ & 44.3039 \\
& -25 & 0.451 & $M_{2}$ & 44.3039 \\
& +25 & 0.451 & $M_{2}$ & 44.3039 \\
& +50 & 0.451 & $M_{2}$ & 44.3039 \\
\hline
\end{tabular}

\subsection{The Payment Is Made at $M_{2}$}

From (4.30), $t_{1,1, M_{2}}=0.424$ which is not feasible as $t_{1,1, M_{2}}>\mu$. Since $T C_{2,1}(0)=$ $55.6719 \kappa \alpha \iota T C_{2,1}(\mu)=46.2334$, it follows that $t_{1,1, M_{2}}^{*}=\mu$. From (4.32), $t_{1,2, M_{2}}=0.424$ which is valid again as $\mu<t_{1,2}<M_{2}$ so $t_{1,2, M_{2}}^{*}=0.424$ and $T C_{2,2}\left(t_{1,2, M_{2}}^{*}\right)=44.3497$. From (4.34), $t_{1,3, M_{2}}=0.451$; this value for $t_{1}$ is also valid as $\mu<M_{2}<t_{1,3}<T$ so $t_{1,3, M_{1}}^{*}=t_{1,3, M_{1}}$ and $T C_{2,3}\left(t_{1,3, M_{1}}^{*}\right)=44.3039$.

Finally $T C_{2,3}\left(t_{1,3, M_{2}}^{*}\right)=\min \left\{T C_{2,1}(\mu), T C_{2,2}\left(t_{1,3, M_{2}}^{*}\right), T C_{2,3}\left(t_{1,3, M_{2}}^{*}\right)\right\}=44.3039$, and consequently $t_{1, M_{2}}^{*}=0.451$.

So, as $T C_{2}\left(t_{1, M_{2}}\right)=\min \left\{T C_{1}\left(t_{1, M_{1}}\right), T C_{2}\left(t_{1, M_{2}}\right)\right\}$, the optimal $t_{1}$ is $t_{1}^{*}=t_{1, M_{2}}^{*}=0.451$, which leads to a payment at $M_{2}$.

Using the data of the previous example, a sensitivity analysis is carried out to explore the effect of change on some, of the basic, model's parameters $\left(\mu, M_{1}, M_{2}, T, r\right)$ to the optimal policy (i.e., $t_{1}$ time of payment and optimal total cost). The results are presented in Table 1 and some interesting findings are summarized as follows.

(1) The changes of parameters $M_{1}, M_{2}$ and $r$ have no impact on the optimal $t_{1}$, the time of payment and the optimal cost.

(2) The error on the parameters' estimation of $\mu$ has no impact on the time of payment, small impact on the optimal $t_{1}$, but high impact on the total optimal cost. This last observation is in line with the relative findings in Deng et al. [21].

\section{Conclusions}

In this paper, the following interrelated factors, which have appeared in the literature of inventory control, are incorporated: (i) the product's life cycle, which implies that its demand can be described as a ramp-type function of time, (ii) the effect of deterioration, (iii) the 
$r / M_{1} / M_{2}$ credit scheme, which can be offered by supplier to the retailer for stimulating the demand, and (iv) the diminished, with the waiting time, backlogging rate, which is described as a decreasing function of time. As a result, this paper is a modification of the inventory system presented by Skouri et al. [23] when the $r / M_{1} / M_{2}$ credit scheme is considered. The study of this system requires the examination of the ordering relations between the time parameters $M_{1}, M_{2}, \mu, T$, which, actually, lead to the six different models. This inventory system, setting $f(t)=D_{0} t, \beta(x)=1, M_{1}=M_{2}=0, I_{p}=0$, and $I_{c}=0$, can give as special cases the ones presented by Mandal and Pal [18], Wu and Ouyang [19], and Deng et al. [21]. This model could be extended assuming several replenishment cycles during the planning horizon. For this extension, the application of some popular heuristic optimization algorithm (like Particle Swarm Optimization or Differential Evolution) may be useful, [28-30].

\section{Acknowledgment}

The authors thank the research committee of the University of Ioannina for the financial support.

\section{References}

[1] C. K. Jaggi, S. K. Goyal, and S. K. Goel, "Retailer's optimal replenishment decisions with credit-linked demand under permissible delay in payments," European Journal of Operational Research, vol. 190, no. 1 , pp. 130-135, 2008.

[2] S. K. Goyal, "Economic order quantity under conditions of permissible delay in payments," Journal of the Operational Research Society, vol. 36, no. 4, pp. 335-338, 1985.

[3] S. P. Aggarwal and C. K. Jaggi, "Ordering policies of deteriorating items under permissible delay in payments," Journal of the Operational Research Society, vol. 46, pp. 658-662, 1995.

[4] A. M. Jamal, B. R. Sarker, and S. Wang, "An ordering policy for deteriorating items with allowable shortage and permissible delay in payment," Journal of the Operational Research Society, vol. 48, no. 8, pp. 826-833, 1997.

[5] H. J. Chang and C. Y. Dye, "An inventory model for deteriorating items with partial backlogging and permissible delay in payments," International Journal of Systems Science, vol. 32, no. 3, pp. 345-352, 2001.

[6] J. T. Teng, "On the economic order quantity under conditions of permissible delay in payments," Journal of the Operational Research Society, vol. 53, no. 8, pp. 915-918, 2002.

[7] M. Y. Jaber, "Lot sizing with permissible delay in payments and entropy cost," Computers $\mathcal{E}$ Industrial Engineering, vol. 52, no. 1, pp. 78-88, 2007.

[8] L. Y. Ouyang and M. C. Cheng, "Optimal ordering policy for a retailer when delay in payments is permissible," International Journal of Information and Management Sciences, vol. 19, no. 3, pp. 437-453, 2008.

[9] K. J. Chung and C. K. Huang, "An ordering policy with allowable shortage and permissible delay in payments," Applied Mathematical Modelling, vol. 33, no. 5, pp. 2518-2525, 2009.

[10] Y. F. Huang, "Buyer's optimal ordering policy and payment policy under supplier credit," International Journal of Systems Science, vol. 36, no. 13, pp. 801-807, 2005.

[11] J. J. Liao, "An EOQ model with noninstantaneous receipt and exponentially deteriorating items under two-level trade credit," International Journal of Production Economics, vol. 113, no. 2, pp. 852-861, 2008.

[12] J. T. Teng and C. T. Chang, "Optimal manufacturer's replenishment policies in the EPQ model under two levels of trade credit policy," European Journal of Operational Research, vol. 195, no. 2, pp. 358-363, 2009.

[13] C. T. Chang, L. Y. Ouyang, and J. T. Teng, "An EOQ model for deteriorating items under supplier credits linked to ordering quantity," Applied Mathematical Modelling, vol. 27, no. 12, pp. 983-996, 2003.

[14] K. J. Chung and J. J. Liao, "The optimal ordering policy of the EOQ model under trade credit depending on the ordering quantity from the DCF approach," European Journal of Operational Research, vol. 196, no. 2, pp. 563-568, 2009. 
[15] L. Y. Ouyang, J. T. Teng, S. K. Goyal, and C. T. Yang, "An economic order quantity model for deteriorating items with partially permissible delay in payments linked to order quantity," European Journal of Operational Research, vol. 194, no. 2, pp. 418-431, 2009.

[16] C. T. Chang, J. T. Teng, and S. K. Goyal, "Inventory lot-size models under trade credits: a review," Asia-Pacific Journal of Operational Research, vol. 25, no. 1, pp. 89-112, 2008.

[17] R. M. Hill, "Inventory models for increasing demand followed by level demand," Journal of the Operational Research Society, vol. 46, no. 10, pp. 1250-1259, 1995.

[18] B. Mandal and A. K. Pal, "Order level inventory system with ramp type demand rate for deteriorating items," Journal of Interdisciplinary Mathematics, vol. 1, no. 1, pp. 49-66, 1998.

[19] K. S. Wu and L. Y. Ouyang, "A replenishment policy for deteriorating items with ramp type demand rate," Proceedings of the National Science Council, Republic of China, Part A, vol. 24, no. 4, pp. 279-286, 2000.

[20] K. S. Wu, "An EOQ inventory model for items with Weibull distribution deterioration, ramp type demand rate and partial backlogging," Production Planning and Control, vol. 12, no. 8, pp. 787-793, 2001.

[21] P. S. Deng, R. H. J. Lin, and P. Chu, "A note on the inventory models for deteriorating items with ramp type demand rate," European Journal of Operational Research, vol. 178, no. 1, pp. 112-120, 2007.

[22] S. Panda, S. Saha, and M. Basu, "An EOQ model with generalized ramp-type demand and Weibull distribution deterioration," Asia-Pacific Journal of Operational Research, vol. 24, no. 1, pp. 93-109, 2007.

[23] K. Skouri, I. Konstantaras, S. Papachristos, and I. Ganas, "Inventory models with ramp type demand rate, partial backlogging and Weibull deterioration rate," European Journal of Operational Research, vol. 192, no. 1, pp. 79-92, 2009.

[24] S. Panda, S. Saha, and M. Basu, "Optimal production stopping time for perishable products with ramp-type quadratic demand dependent production and setup cost," Central European Journal of Operations Research, vol. 17, no. 4, pp. 381-396, 2009.

[25] K. Skouri and I. Konstantaras, "Order level inventory models for deteriorating seasonable/fashionable products with time dependent demand and shortages," Mathematical Problems in Engineering, Article ID 679736, 24 pages, 2009.

[26] S. W. Lin, "Inventory models with managerial policy independent of demand," European Journal of Operational Research, vol. 211, pp. 520-524, 2011.

[27] J. T. Teng, H. J. Chang, C. Y. Dye, and C. H. Hung, “An optimal replenishment policy for deteriorating items with time-varying demand and partial backlogging," Operations Research Letters, vol. 30, no. 6, pp. 387-393, 2002.

[28] K. E. Parsopoulos, K. Skouri, and M. N. Vrahatis, "Particle swarm optimization for tackling continuous review inventory models," Lecture Notes in Computer Science, vol. 4974, pp. 103-112, 2008.

[29] T. P. Hsieh and C. Y. Dye, "A particle swarm optimization for solving joint pricing and lotsizing problem with fluctuating demand and unit purchasing cost," Computers \& Mathematics with Applications, vol. 60, no. 7, pp. 1895-1907, 2010.

[30] C. Y. Dye and L. Y. Ouyang, "A particle swarm optimization for solving joint pricing and lot-sizing problem with fluctuating demand and trade credit financing," Computers $\mathcal{E}$ Industrial Engineering, vol. 60, no. 1, pp. 127-137, 2011. 


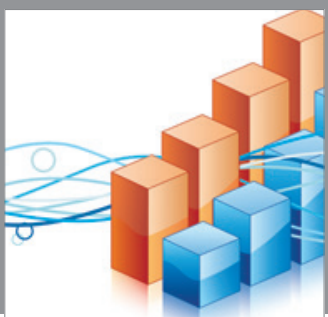

Advances in

Operations Research

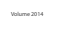

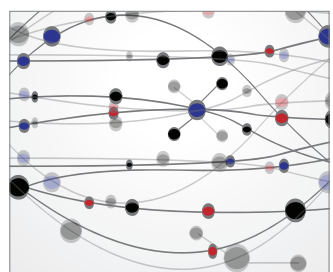

\section{The Scientific} World Journal
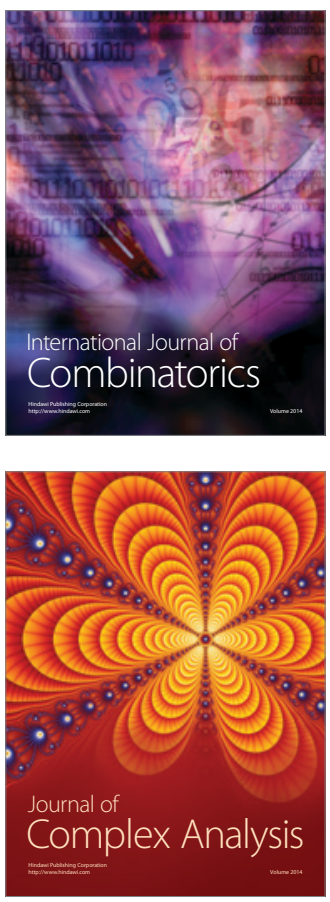

International Journal of

Mathematics and

Mathematical

Sciences
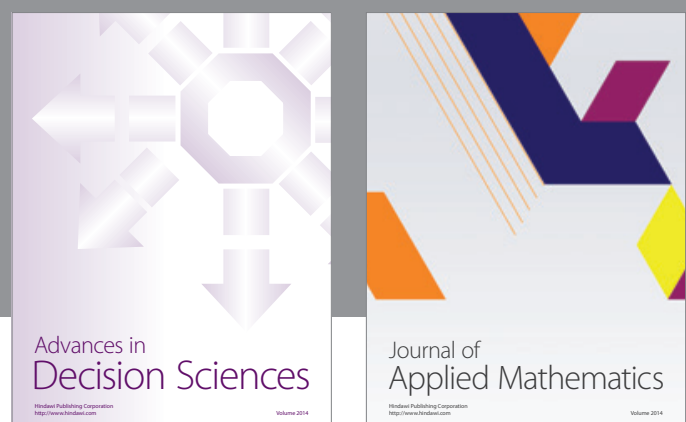

Journal of

Applied Mathematics
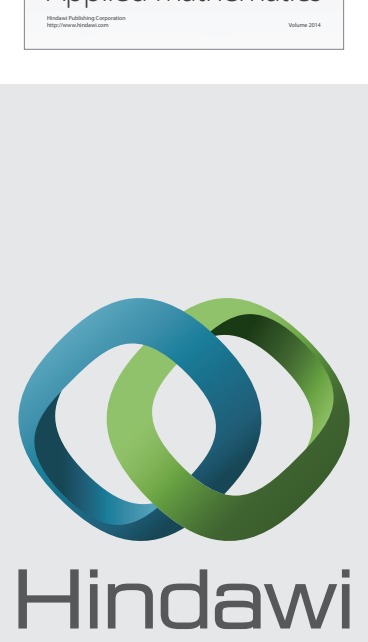

Submit your manuscripts at http://www.hindawi.com
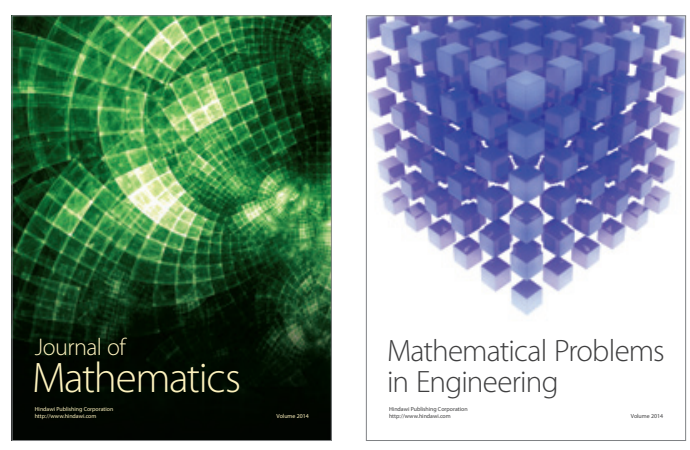

Mathematical Problems in Engineering
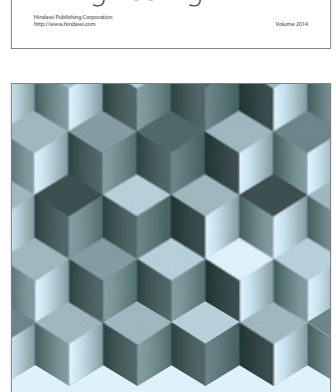

Journal of

Function Spaces
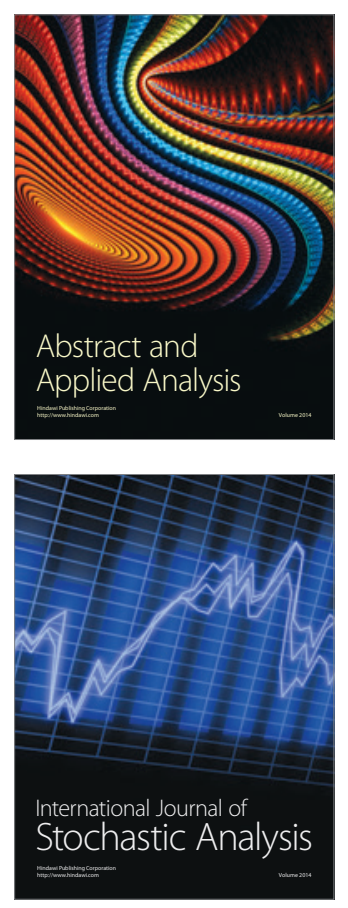

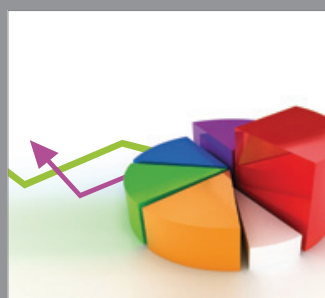

ournal of

Probability and Statistics

Promensencen
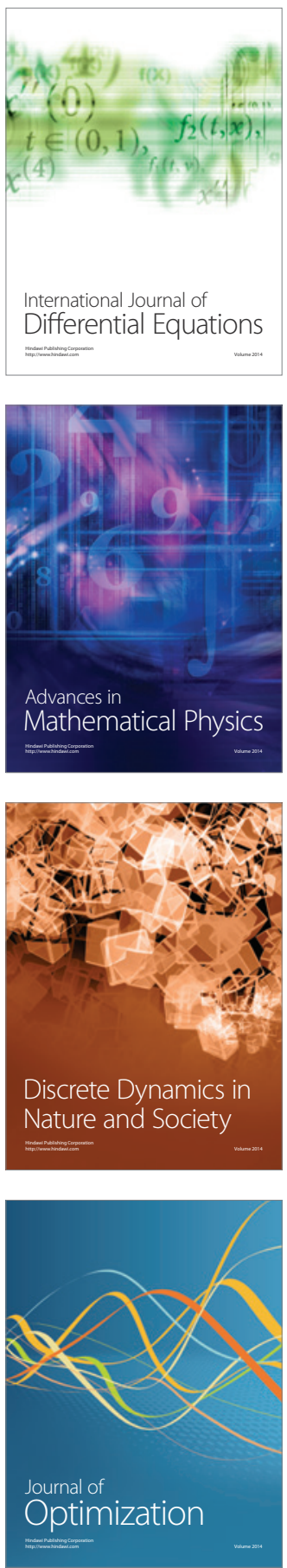